\title{
Concept of Computational Fluid Dynamics (CFD) and its Applications in Food Processing Equipment Design
}

\section{Pragati Kaushal* and Sharma HK}

Department of Food Engineering and Technology, Sant Longowal Institute of Engineering \& Technology (Deemed to be University), Longowal-148106, Distt, Sangrur (Punjab), India

\begin{abstract}
CFD is a simulation tool used to model fluid flow simulations which involves the use of powerful computers and applied mathematics for predicting heat and mass transfer in various processes. In recent years it has been applied in food processing equipment design. This paper reviews the applications of CFD in food processing including cleaning of storage tanks, designs of dryers, sterilizers, freezers, mixers etc. The advantages and disadvantages of using CFD are discussed along with its future in food processing industry.
\end{abstract}

\section{Computational Fluid Dynamics (CFD)}

CFD is a simulation tool used to predict what will happen, quantitatively when fluids flow, often with the complication of simultaneous flow of heat, mass transfer, phase change (melting, freezing, boiling), chemical reaction (combustion, rusting), mechanical movement of (pistons, fans etc.), stresses in and displacement of immersed or surrounding solids. CFD uses a computer to solve the relevant science-based mathematical equation, using information about the circumstances in question.

\section{Performing a CFD Analysis}

It is done in three stages: preprocessing, processing and post processing. In pre-processing step, all the tasks that take place before the numerical solution process. This includes problem thinking, meshing and generation of a computational model. Processing involves using a computer to solve mathematical equations of fluid flow. This is a very intensive process and usually it requires the computer to solve many thousands of equations. In each case, the equations are integrated and boundary conditions are applied to it. In post-processing step, this program is used to make evaluation of the data generated by CFD analysis. When the model has been solved, the results can be analyzed both numerically and graphically.

\section{CFD Applications in Various Areas}

CFD uses powerful computers and applied mathematics to model fluid flow situations. The state of success is how well the results of numerical simulation agree with experiment in cases where careful laboratory experiments can be established, and how well the simulations can predict highly complex phenomena that cannot be isolated in the laboratory [1]. As a result, CFD has become an integral part of the engineering design and analysis environment of many companies because of its ability to predict the performance of new designs or processes before they are ever manufactured or implemented [2]. Several areas of CFD applications includes architecture, chemical and process engineering, electronics and computer, HVAC (heat, ventilation \&cooling), petroleum, train design, turbo machinery etc. Its physiological applications includes cardiovascular flow (Heart, major vessels), flows in lungs and breathing passages. However, it is only in recent years that CFD has been applied in the food processing area [3]. Since CFD technique can be of great benefit to the food processing industry, fast development has taken place in the past few years. CFD, as a tool of research for enhancing the design process and understanding of the basic physical nature of fluid dynamics can provide benefits to the food processing industry in many areas, such as drying, sterilization, mixing, refrigeration and other application areas.

\section{CFD Applications in Food Processing}

CFD applications in food industry may assist in a better understanding of the complex physical mechanisms. Schott $[4,5]$, Quarini [6] have reviewed the general application of CFD to the food processing industry. Moreover, other literatures are also available on specific CFD application areas such as: Clean-room design, Refrigerated transport [7], Static mixers [4], and Pipe flow [8]. Since CFD technique can be of great benefit to the food processing industry, fast development has taken place in the past few years. CFD, as a tool of research for enhancing the design process and understanding of the basic physical nature of fluid dynamics [9] can provide benefits to the food processing industry in many areas, such as drying, sterilization, mixing, refrigeration and other application areas.

\section{Improving the Cleaning of Food Processing Tanks}

Tanks are used in food production plants for many purposes: storage of raw materials and end products, buffer for intermediate products, fermentation, mixing, heating and cooling. In severe cases, poor cleaning can cause biofilm formation on equipment surfaces, which can cause corrosion and health problems, therefore tanks must be clean at the starting point. The challenge is to optimize the design of cleaning systems with respect to their efficiency and economy and to optimize parameters in CIP - cleaning procedures, improve hygienic design by simulating flows in tanks, spray balls and pipes with CFD,

${ }^{*}$ Corresponding author: Pragati Kaushal, Department of Food Engineering and Technology, Sant Longowal Institute of Engineering \& Technology (Deemed to be University), Longowal-148106, Distt, Sangrur (Punjab), India Tel: +91-9888412812; E-mail: pragati_gndu@yahoo.co.in

Received November 02, 2011; Accepted December 08, 2011; Published December 12, 2011

Citation: Kaushal P, Sharma HK (2012) Concept of Computational Fluid Dynamics (CFD) and its Applications in Food Processing Equipment Design. J Food Process Technol 3:138. doi:10.4172/2157-7110.1000138

Copyright: () 2012 Kaushal P, et al. This is an open-access article distributed under the terms of the Creative Commons Attribution License, which permits unrestricted use, distribution, and reproduction in any medium, provided the original author and source are credited. 
find practical detection methods to study cleanability and also for routine quality control. However performing a numerical simulation of the flow through the junction yields the velocity distribution from which the shear stresses along the walls are deduced. Although the quantification of the cleaning performance related to local shear stress values is difficult, especially due to the statistical nature of the test results and the modeling of the turbulent boundary layer along the walls in the simulation. However, after a preliminary quantification of the results of the numerical simulations CFD can be used to compare results for geometrically different junctions and hence enables the engineer to improve the design at an early stage, without the necessary tests: these tests are limited to the final, optimized design only. Asteriadou et al. [10] used CFD to assess the cleanability of a T-junction. Electrical conductivity measurements of a salt solution of known concentration before and after the $\mathrm{T}$-junction were cleaned using deionized water. This comparison gave an acceptable qualitative agreement with finite volume-based calculations that involve both steady-state and transient operations. This approach was a necessary prerequisite for the development of models that will ultimately include bacterial growth and deactivation kinetics under processing conditions.

\section{Applying CFD in Optimization of Hygiene}

CFD is a useful tool for optimization of hygienic design of closed process equipment. A combination of wall shear stress, fluid exchange and turbulence conditions can predict areas which are not properly cleaned. Also surface topography, material properties, the specific microbiological flora and other component of soil have an influence on the cleaning efficiency. The most successful ways of prevention microbiological contamination is to ensure that proper cleaning is performed. Results from CFD simulations yield information about wall shear stresses in the tank and the flow rates in different parts of the system. The results from the experiments studying a simple case revealed similar trends from traditional cultivations and CFD. This has given a support to the hypothesis that a combination of knowledge in fluid dynamics and microbiology gives an excellent base for hygienic of integrated tank and CIP cleaning systems.

\section{Drying}

Drying is a common food manufacturing process. The drying rate is a strong function of air flow or air velocity. Therefore, it is of great importance to know the air flow and velocity in the drying chamber, thus leading to know the areas of adequate air velocities for proper drying. However, air flow and air velocity are difficult to measure during operation because several sensors are needed to be placed at various directions of air flow and locations. Cereals and oilseeds are dried after harvest to the moisture content that allows microbial stability during storage. Vegetables are blanched before drying to avoid rapid darkening, and drying is not only carried out to inhibit microbial growth, but also to avoid development of browning in storage. Since there are some difficulties in modelling the complex phenomena, especially the gas turbulence [11]. CFD is a powerful tool to aid the prediction of drying process therefore can be used to predict the air flow and velocity during drying. Determination of pressure profiles and air velocities by CFD showed that the main cause of the variations in drying rates and moisture contents was the lack of spatial homogeneity of air velocities within the drier. Although the flow pattern and air velocity in the drier can be predicted using CFD modeling, further study on how to control the drying process and to reduce the energy cost is still a research topic for CFD modelling. Meanwhile, more attention should be paid on the assumptions such as spatial homogeneity [12] because of such assumptions could lead to inaccuracy in prediction.

CFD has also been used to investigate the performance and design of spray dryers in the food industry. Zbicinski [13] developed a mathematical model of momentum, heat and mass transfer during spray drying. He used CFX code to determine a model of air flow in the dryer and these results were used to calculate particle trajectories and to solve the heat and mass balance for the continuous and dispersed phases. The model predictions were in good agreement with the experimental results. Langrish et al. [14], Fletcher et al. [15] reviewed the applications of CFD in spray drying operations to predict flow patterns and temperature distributions of gas and droplets. Huang et al. [16] investigated the air flow patterns, temperature, velocity and humidity profiles at different level in a co-current spray dryer using FLUENT code. Zbicinski and Zietara [17] presented a twodimensional, fully coupled, axisymmetrical steady-state CFD model of counter-current spray drying process where agglomeration of discrete phase in the recirculation zones was taken into account. Agglomeration rate was determined on the basis of probability of particle collisions and density distribution of dispersed phase in the calculation domain. Experimental distributions of particle size and velocities of particle fractions, random spraying angle, heat losses to the environment, etc. were incorporated into the calculations. The regions of agglomeration and wall deposition were identified in the drying column. Theoretical and experimental results were analyzed and compared.

Simon Lo [18] used computational fluid dynamics (CFD) in the analysis of spray dryers. The Euler-Lagrange model was used to compute the motions of the spray droplets and the heat and mass transfers between the droplets and the air stream. Extreme useful results were extracted from the CFD and presented in percentages of particles leaving the particle and air exits, and the particle conditions at these exits in terms of mean diameter, temperature and moisture content. From these results, the operator of the dryer can easily select the optimum operating conditions, which allows him to achieve the desired product quality at minimum cost. Huang et al. [19] studied the effects of rotary atomizer and pressure nozzle on velocity, temperature and humidity profiles in a co-current spray dryer. Anandharamakrishan et al. [20] showed in a 3D model of tall farm spray drying, particle adherence to the wall of the spray dryer was more and it adversely affects the product quality.

Rinil et al. [21] reviewed the applications of computational fluid dynamics (CFD) in the area of spray drying. He observed that CFD can be a useful tool for predicting the gas flow pattern and particle histories such as temperature, velocity, and residence time and impact position. Moreover, CFD can also be used for investigating different chamber design on drying behaviour of food materials as well as scale-up studies, air-particle interactions, different turbulence models, reference frames, reaction engineering model used for spray-drying applications along with the particle histories and different spray chamber configurations. This also highlights the recent developments in this research area such as drying kinetics model, droplet-droplet interactions, unsteady state simulations and integration of population balance model.

\section{Pasteurization}

Pasteurization is a vital unit operation which is used to inactivate the spoilage organisms and enzymes present in the milk. Denys et al. 
[22] conducted CFD analysis for thermal pasteurization of intact eggs. Calculated temperature profiles were found to be in good agreement with experimentally observed data for eggs of different sizes. A generally accepted kinetic inactivation model for Salmonella enteritidis was incorporated in the CFD analysis and provided a basis for process assessment. Minimum process times and temperatures to provide equivalent pasteurization effectiveness at $5 \log$ reductions of the target microorganism were obtained on a theoretical basis. Combining a CFD analysis with inactivation kinetics proved to be a very useful approach for establishing process conditions leading to consumer safe eggs.

Paul et al. [23] conducted CFD modeling to determine the temperature distribution pattern inside canned milk during thermal processing. In this study, a CFD model was developed for the pasteurization process of canned milk at $74^{\circ} \mathrm{C}$ and $85^{\circ} \mathrm{C}$ and validated with the experimental measurements. Moreover, the effect of can rotation (5, 50 and $100 \mathrm{rpm})$ on processing time and pasteurization value was investigated. This study predicted rotation of can with $5 \mathrm{rpm}$ was more effective than stationary positioned can during pasteurization.

Augusto et al. [24] conducted in-package pasteurization for beer microbiological stabilization. A heating process was simulated at $60^{\circ} \mathrm{C}$ up to 15 PUs (a conventional beer process, in which 1 Pasteurization Unit (PU) is equivalent to 1 minute at $60^{\circ} \mathrm{C}$ ). The temperature profile and convection current velocity along the process and the variation of the PUs were evaluated in relation to time considering the cans in the conventional, inverted, and horizontal positions. The package position did not result in process improvement.

\section{Sterilization}

Sterilization is an important technique for food storage and preservation. CFD can be used to study both the temperature distribution and flow pattern of food in the process of sterilization so as to optimize the quality of food products. Thermal processing is the most significant technique of sterilization which results in microbial inactivation, but sometimes results in quality loss and flavor development. Excessive heating will affect food quality and its nutritional properties. With the application of CFD, there has been number of studies to optimize the thermal sterilization of foods [25-29]. These studies had led to substantial improvement on the optimal control of the process and the retention of the nutritional and sensory quality of food. CFD code was used for the purpose to simulate the transient temperature, velocity profiles, and shape of the slowest heating zone in sterilization of carrot soup in pouches [30]. However, all of these investigations about CFD application in sterlization are on the thermal sterlization in the limited area of liquid foods.

Natural convection heating within a can of liquid food during sterilization was simulated by solving the governing equations for continuity, momentum and energy conservation for an axisymmetric case using a commercial Computational Fluid Dynamics (CFD) package (PHOENICS) by Ghani et al. [31]. Transient flow patterns and temperature profiles within model liquids (sodium carboxy-methyl cellulose (CMC) and water had been predicted. It was observed that the action of natural convection forces the slowest heating zone (SHZ) to migrate towards the bottom of the can as expected. The shape and the size of the SHZ area are different for $\mathrm{CMC}$ and water. The magnitude of the axial velocity was found to be in the range of $10^{-5}-10^{-4} \mathrm{~m} / \mathrm{s}$ for CMS and of $10^{-2}-10^{-1} \mathrm{~m} / \mathrm{s}$ for water, these magnitudes of course vary with time and position in the can.
Tattiyakul et al. [32] analyzed the simulation of heat transfer to a canned corn starch dispersion subjected to axial rotation in finite element method. They concluded that rotation at the higher speed prevented heat transfer in the radial direction and yielded the slowest heat penetration rate. Abdul Ghani et al. [33] investigated the thermal destruction of Vitamin C in food (carrot orange soup) in pouches. The temperature and concentration profiles of Vitamin $\mathrm{C}$ were strongly influenced by convection. They found that migration of SHZ towards the bottom of pouch as heating proceeds and also the dependence of Vitamin $\mathrm{C}$ concentration on both temperature distribution and flow pattern. Abdul Ghani et al. [31] studied the effect of can rotation on sterilization of liquid food (carrot-orange soup). The simulation process was carried out on a metal can lying horizontally and rotated axially at $10 \mathrm{rpm}$ in a still retort. They concluded that the rotation of the can had a significant effect on the shape, size and location of SHZ. Farid et al. [34] estimated sterilization time of canned food (Carboxy methyl cellulose and carrot-orange soup). They developed a correlation for the prediction of the sterilization time of liquid food in the vertical and horizontal cans.

Varma and Kannan [35] analyzed the effect of sterilization through wall inclination and can geometry modifications. The three different can geometries used for the study were a full cone, truncated zones and a full cylinder. They founded that wall inclination and orientation angle in can geometry had a considerable effect on the performance of the sterilization system. Varma and Kannan [36] studied the natural convective heating of canned food (CMC) in conical and cylindrical containers. Simple modifications to the shape and orientation of the three geometries such as cylinder, cone, cone-inverted on enhancing natural convective heat transfer rates were analyzed. The comparisons among the three geometries showed that the inverted cone gets heated the fastest followed by the cylinder and the cone heated the slowest. Abdul Ghani and Farid [37] analyzed the thermal sterilization of solidliquid food mixture (pineapple slices) in cans. They predicted the flow pattern, temperature distribution and shapes of the slowest heating zone during heating of solid-liquid food mixture.

Kannan and Gourisankar Sandaka [38] carried out heat transfer analysis of canned food (CMC) sterilization in a still-retort. They concluded that the heat transfer coefficients based on volume averaged temperatures was more convenient to use than absolute mass flow averaged ones. Shahsavand and Nozari [39] investigated the simulation of a Continuous Thermal Sterilization (CTS) process for both laminar and turbulent flow regimes. Various heuristics were considered for the reliable estimation of sterility (F value) and quality (C value) parameters. It was proved that for a laminar condition that using a mixer at the entrance of the holding zone can drastically increase the sterility of food produce while reducing its quality degradation. For a turbulent flow regime, the effect of trajectories and thermal resistances of solid particles on the performance of the CTS process was investigated. It was observed that the thermal resistances of relatively large particles have a crucial effect on computed values of both sterility and quality parameters.

There are still many challenges in the area of sterlization with application of CFD for instance, Ultra-Violet, Visible and Infrared light surface sterilization, plasma/corona sterilization, electrons and $\mathrm{X}$-rays sterlization, nascent oxygen/ozone sterlization of fruits and vegetables, pressure sterlization of fresh fruit juices and cooked ham. The application of CFD in these sterilization fields of food is still to be developed in future. 


\section{Mixing}

Mixing applications involve the substances of gas, liquid and solid. However, mixing is a complicated process as regards to the multiphase turbulence during mixing and the design of a mixer. CFD is a powerful tool for the modelling of mixing processes. It provides a natural method to link food process and fluid flow information, the phenomena in an agitated vessel can be predicted [40]. All types of mixers do some work on the material being mixed and produce some increase in temperature. It is often desirable to minimize this temperature rise. However mixers are chosen to do special kinds of work on heavy viscous materials while they are being mixed. These working mixers are designed with precise geometries to maximize the efficiency and minimize the energy requirements to achieve the mixing working operation. During mixing, a common method of enhancing the process is to use some kind of stirrer or paddle. CFD codes have been applied in optimizing the mixing process to minimize energy input and to shorten processing time. Recently, CFD modelling has been used to study impeller-vessel geometry, energy balance, linkage between the flow fields. The effect of multiple Intermig impeller configurations on hydrodynamics and mixing performance in a stirred tank had been investigated using computational fluid dynamics. Connection between impeller stages and compartmentalization were assessed using Lagrangian particle tracking. The results showed that by a rotating Intermig impeller by $45^{\circ}$ respect to its neighbours, instead of a $90^{\circ}$ rotation as recommended by manufacturers, enables a larger range of operating conditions, i.e. lower Reynolds number flows, to be handled. Furthermore by slightly decreasing the distance between the lower two impellers, fluid exchange between the impellers is ensured down to $\mathrm{R}_{e}=27$ [41].

\section{Baking}

It is a term commonly used for the production of cereal based products such as bread, biscuits etc. and generally applied to the production of fermented bread. Baking is the process of the conversion of some relatively unpalatable ingredients (starch, gluten etc.) into aerated, open cell structure bread which involves the simultaneous heat and mass transfer where heat is transferred into the food from the hot surfaces and air in the oven and moisture is transferred from the food to air that surrounds it and then removed from the oven. De Vries et al. [42] calculated temperature, heat flux, velocity distribution and pressure distribution inside the baking oven assuming laminar air flow.

In a typical indirect-heating continuous baking oven, the dough/ bread effectively experiences four major heating zones. The temperature profile in the four zones is critical because temperature in each zone is the dominating factor on the baking mechanisms including gelatinization, enzymatic reactions etc. therefore the final bread quality is affected [43]. In another study, Therdthai et al. [44] developed a 2-dimensional industrial continuous baking oven for the study of temperature and air flow patterns throughout the baking chamber under different operating conditions including different energy supply, fan volume; the heat distribution trend in the oven was satisfactorily simulated. Based on the simulation results, positioning of the controller sensors were investigated through a sensitivity study. The simulation results are used to modify the oven configuration for better heat distribution.

Zhang and Datta [45] developed a mathematical model for large volume change for multiphase transport in a porous medium based on the conservation of energy and three mass species of liquid water, water vapour and $\mathrm{CO}_{2}$ gas. The CFD analysis of flow and temperature distribution in heating ovens used in bakery shop was studied by Navaneethakrishnan et al. [46] using finite element technique. The oven was modelled as a two-dimensional steady state natural convection heat transfer problem. Effects of heater location and total heat input on temperature uniformity of foodstuffs are studied. Placing the heater at the bottom of the oven improves the air circulation rate by 17 times and 10 times than that at the top and side of the oven. But the top location provides better uniformity in foodstuff temperature than the other cases. Side location was not preferable. The analysis shows that if heaters are located at the bottom along with additional flow guidance arrangements, energy efficient oven configuration can be obtained.

Wong et al. [47] developed a 2D CFD model aiming to eliminate some of the existing simplifications and assumptions in the earlier work by Therdthai et al. [48]. They successfully kept the basic feature of U- turn continuous movement of travelling tray by using sliding mesh technique. These mathematical and CFD models reduce the possible work and the energy less encountered with trial and error experimentations and at the same time, it serves as a practical tool for design, optimization and validation of the process control. Therefore, CFD can be used for design, scale up and optimization of baking ovens. However selection of the geometry, turbulence model and the physical properties inputs may have a significant impact on the accuracy of the simulation results. Therefore, great care should be taken in CFD modeling to minimize the error.

\section{Refrigeration}

The process can slow down bacterial growth and preserve food. Therefore, researchers have recently applied CFD in the modelling of heat and mass transfer in foods during refrigeration (chilling and freezing). Factors affecting accuracy of CFD modeling includes: temperature, different models, thermocouple positions etc. CFD designs can examine whole range of modifications before manufacturing, designing at a minimal cost and in a short time [49]. Refrigerated foods require strict control over temperature, design of equipment or stores for refrigerated foods are very important for the utilization of CFD, designers can examine the whole range of modifications before manufacturing and designing at minimal cost and in as short time [50]. CFD being the powerful simulation tool to analyze and solve the problems, is one filiations of the fluid dynamics which uses computer to evaluate momentum, heat, mass and other control equations of fluid in the fixed geometry space for getting the useful message in the given conditions [51].

Smale et al. [52] reviewed the applications of CFD and other numerical modelling techniques to the prediction of airflow in refrigerated food applications including cool stores, transport equipments and retail display cabinets. Lv et al. [53] developed the CFD model based on the fundamental equations of conservation of mass and energy to describe the flow patterns of airflow and the process of heat and mass transfer for a vertical turbulent buoyant jet to evaluate the energy performance of the air curtain for horizontal refrigerated display cabinets. The CFD method was also validated with experimental tests performed in accordance with the EN441 Standard which helps in the optimization design and experiments on display cabinets. CFD optimization of air flow in refrigerated truck configuration loaded with pallets was done by Jean Moureh [54] aims to improve and optimize the 
air-distribution systems in refrigerated vehicles in order to decrease the temperature differences throughout the palletized cargos which in turn is essential to preserve the quality, safety and shelf-life of perishable products.

\section{Heat Exchangers}

A heat exchanger is a device built for efficient heat transfer from one medium to another. In order to predict and control food quality during heating process, CFD has been used to simulate and study the flow distribution and temperature distribution of fluid. The trend towards aseptic processing, combine with the aim of minimizing cooked flavors in heat processed products is leading heat exchangers to be constantly redesigned and improved. In this case, CFD can be used to optimize such redesign of heat exchangers. Traditionally, CFD analysis has been applied to simulate the flow of a fluid around obstacles and through hollow areas in order to control temperatures, reduce resistance to flow and/or optimize phenomena such as lift. Khudheyer and Mahmoud [55] conducted three-dimensional CFD simulations to investigate heat transfer and fluid flow characteristics of a two-row plain fin-and-tube heat exchanger using Open FOAM, an open-source CFD code. Heat transfer and pressure drop characteristics of the heat exchanger were investigated for Reynolds numbers ranging from 330 to 7000. The most accurate simulations for heat transfer in laminar flow are found using the laminar flow model, while heat transfer in transitional flow is best represented with the SST k-omega turbulence model, and heat transfer in turbulent flow is more accurately simulated with the k-epsilon turbulence model. Reasonable agreement was found between the simulations and experimental data, and the open-source software has been sufficient for simulating the flow fields in tube-fin heat exchangers.

\section{Other Equipment Designs}

CFD can be used for other equipment designs, for detailed product development and for scale-up the process. For example, Baerdemaeker [56] discussed the equipment considerations for sous vide cooking. Janes [57] reviewed the art of bakery equipment manufacture and use of CFD in the design as well as set up of baking ovens.

\section{Crystallization}

It is one of the oldest unit operation in the chemical and food industry but the design and operation of crystallization processes still pose many problems. However, until recently, there have been few tools capable of providing the required capabilities. This is because modelling of crystallization processes poses a number of challenges. The key challenge is representing the inherent physical and chemical complexity of crystallization phenomena mathematically and validating the resulting mathematical model against experimental data.CFD helps in modelling of crystallization process and design of crystallizer.

\section{Advantages of using CFD}

1. It provides a detailed understanding of flow distribution weight losses, mass and heat transfer, particulate separation etc [49].

2. It makes it possible to evaluate geometric changes with much less time and cost than would be involved in laboratory testing [49].

3. It is able to reduce scale-up problems because the models are based on fundamental physics and are scale independent [49].

4. It is particularly useful in simulating conditions where it is not possible to take detailed measurements such as high temperature or dangerous environment in an oven [49].

5. It provides flexibility to change design parameters without changing actual system changes thereby allowing engineers to try more alternative designs which would be feasible [58].

6. It allows the analyst to examine large number of locations in particular region of interest [58].

7. It provides a great deal of credibility in food industry and has been integrated in main stream of design and analysis [59].

8. CFD results can provide the necessary confidence which other simulating tools are unable to provide [59].

9. It helps in modifying the design of various equipments like spray drier. Here CFD is used to analyze the performance of industrial spray drier so as to make necessary changes to drier when possible [59].

10. CFD offers low cost than the physical testing methods which help in understanding essential engineering data for design which can be expensive [59].

\section{Application Problems}

Food designers are increasingly using the software tools to produce new food products. Therefore one has to face several problems while using CFD. This requires the use of powerful CFD packages, high speed computers, well-versed CFD experts, accurate algorithm for the equations of motion. These problems hinder the widespread use of CFD. Moreover Conventional CFD packages include features which can predict only 'mixture-average' properties of food but unable to predict physico-chemical properties. Therefore, the biggest problem in CFD is probably not the mesh generation, nor the necessary computer power or the CFD solvers, but to find the people who really can do the full job. It is expected that considerable demand for specialists to apply and develop CFD methods throughout the food industry [60].

\section{Conclusions}

CFD can be used as a tool for design of food processing equipment. Its applications include the cleaning of storage tanks, crystallization, conventional cyclones, drying, sterilization, crystallization, mixing and refrigeration, fermentation, baking etc. But its effectiveness and practicability depend on several factors like powerful CFD packages, high speed computers, well-versed CFD experts etc. However, the simulation results should be rechecked by experiments because CFD use many approximate models as well as few assumptions. There are still some obstacles such as inability in accurate simulation of large 3-D problems on an affordable computer, particularly in large-scale sophisticated plants. But its trend of widespread applications in the food processing industry is expected to rise in the $21^{\text {st }}$ century.

\section{References}

1. Sethian JA (1993) Computational Fluid Dynamics In: from Desktop to Teraflop Exploiting the US Lead in High Performance Computing. NSF Publications, National Science Foundation, Washington, DC, USA.

2. Schaldach G, Berger L, Razilov I, Berndt H (2000) Computer simulation fo fundamental studies and optimization of ICP spray chambers. ISAS (Institute of Spectrochemistry and Applied Spectroscopy) Current Research Reports, Berlin, Germany.

3. Scott GM (1994) Computational fluid for food industry. Food Tech International, Europe 1994, 49-51. 
4. Scott GM (1977) Simulation of the flow of non-Newtonian foods using computational fluid dynamics. Campden \& Chorleywood Food Research Association R \& D Report No. 34, Chipping Campden, UK.

5. Scott GM, Richardson P (1997) The application of Computational fluid dynamics in the food industry. Trends in Food Science \& Technology 8: 119-124.

6. Quarini J (1995) Applications of Computational fluid dynamics in food and beverage production. Food Sci Technol Today 9: 234-237.

7. Janes DA, Dalgly EF (1996) How to use CFD in the food industry. Leatherhead Food Research Association Technical Report, Leatherhead, UK.

8. Scott GM (1996) Computational fluid-modeling the flow of Newtonian fluids in pipelines. Campden and Chorleywood Food Research Association R \& D Report No. 34, Chipping Compden, UK

9. Anderson JD (1995) Computational Fluid Dynamics: The Basics with Applications. MC Graw-Hill, Singapore.

10. Asteriadou K, Hasting T, Bird M, Melrose J (2007) Predicting cleaning of equipment using computational fluid dynamics. J Food Eng 30: 88-105.

11. Oakley DE (1994) Scale-up of spray dryers with the aid of computational fluid dynamics. Drying Technol 12: 217-233.

12. Mathioulakis E, Karathanos VT, Belessiotis VG (1998) Simulation of air movement in a dryer by computational fluid dynamics: Application for drying of fruits. J Food Eng 36: 183-200.

13. Zbicinski I (1995) Development and experimental verification of momentum, heat and mass transfer model in spray drying. Chem Eng J \& Biochem Eng $J$ 58: $123-133$

14. Langrish TAG, Fletcher DF (2001) Spray drying of food ingredients and applications of CFD in spray drying. Chem Eng Proc 40: 345-354.

15. Fletcher D, Guo B, Harvie DJE, Langrish TAG, Nijdam JJ, et al. (2006) What is important in the simulation of spray dryer performance and how do current CFD models perform? Applied Mathematical Modelling 30: 1281-1292.

16. Huang LX, Kumar K, Mujumdar AS (2003) A parametric study of the gas flow patterns and drying performance of co-current spray dryer: Results of a Computational fluid Dynamics study. Drying Technol 21: 957-978.

17. Zbicinski I, Zietara R (2004) CFD model of counter-current spray drying process. Drying 2004-Proceedings of the 14th International Drying Symposium (IDS) São Paulo, Brazil A: 169-176.

18. Simon Lo (2005) Application of computational fluid dynamics to spray drying Lait, Dairy Science and Technology 85: 353-359.

19. Huang LX, Kumar K, Mujumdar AS (2006) A comparative study of the spray dryer with rotary disc atomizer and pressure nozzle using Computational Fluid Dynamics Simulations. Chemical Engineering and Processing 45: 461-470.

20. Anandharamakrishan C, Gimbun J, Stapley AGF, Rielly CD (2008) A study of the particle histories during spray drying using Computational Fluid Dynamics Simulations. International Drying Symposium.

21. Rinil, Kuriakose, Anandharamakrishnan C (2010) Computational fluid dynamics (CFD) applications in spray drying of food products. Trends in Food Sci \& Technol 21: 383-398.

22. Denys S, Pieters JG, Dewettinck KL (2005) CFD analysis of heat transfer and microbial lethality during pasteurization of intact eggs. ISHS Acta Hort 674 213-219

23. Paul DA, Anishaparvin A, Anandharamakrishnan C (2010) Computational fluid dynamics studies on pasteurization of canned milk. Int J Dairy Technol 64: 305-313.

24. Augusto PED, Pinheiro TF, Cristianini M (2010) Using Computational FluidDynamics (CFD) for the evaluation of beer pasteurization: effect of orientation of cans. Ciênc Technol Aliment Campinas 30: 980-986.

25. Datta K, Teixeira AA (1987) Numerical modeling of natural convection heating in canned liquid foods. Transactions of the ASAE 30: 1542-1551.

26. Akterian SG, Fikiin KA (1994) Numerical simulation of unsteady heat conduction in arbitrary shaped canned foods during sterilisation process. J Food Eng 21 343-354

27. Abdul Ghania AG, Farid MM, Chen XD, Richards P (1999) Numerical simulation of natural convection heating of canned food by computational fluid dynamics. J Food Eng 41: 55-64.
28. Abdul Ghania AG, Farid MM, Chen XD, Richards P (1999) An investigation of deactivation of bacteria in a canned liquid food during sterilization using computational fluid dynamics (CFD). J Food Eng 42: 207-214.

29. Abdul Ghania AG, Farid MM, Chen XD, Richards P (2001) Thermal sterilization of canned food in a 3-D pouch using computational fluid dynamics. J Food Eng 48: $147-156$

30. Abdul Ghani AG, Farid MM, Chen XD, Richards P (1999) Numerical simulation of natural convection heating of canned food by computational fluid dynamics. J Food eng 41: 55-64.

31. Ghani AG, Farid MM, Chen XD (2003) A computational and experimental study of heating and cooling cycles during thermal sterilization of liquid foods in pouches using CFD. Proc. Institution of Mechanical Engineers, Part E: Process Mechanical Eng 217: 1-9.

32. Tattiyakul J, Rao MA, Datta AK (2001) Simulation of heat transfer to a canned corn starch dispersion subjected to axial rotation. Chemical Engineering and Processing 40: 391-399.

33. Abdul Ghani AG, Farid MM, Chen XD (2002) Theoretical and experimental investigation of thermal inactivation of Bacillus stearothermophilus in food pouches. J Food Eng 51: 221-228.

34. Farid M, Abdul Ghani AG (2004) A new computational technique for the estimation of sterilization time in canned food. Chem Eng Proc 43: 523-531.

35. Varma MN, Kannan A (2005) Enhanced food sterilization through inclination of the container walls and geometry modifications. Int J Heat Mass Transf 48 : 3753-3762.

36. Varma MN, Kannan A (2006) CFD studies on natural convective heating of canned food in conical and cylindrical containers. J Food Eng 77: 1024-1036.

37. Abdul Ghani AG, Farid MM (2006) Using the computational fluid dynamics to analyze the thermal sterilization of solid-liquid food mixture in cans. Innov Food Sci Emerg Technol 7: 55-61.

38. Kannan A, Gourisankar Sandaka P (2008) Heat analysis of canned food sterilization in a still-retort. J Food Eng 88: 213-228.

39. Shahsavand A, Nozari $Y$ (2009) Simulation of a Continuous Thermal Sterilization Process in the Presence of Solid Particles. Transactions C: Chemistry and Chemical Engineering 16: 29-40.

40. Delaplace G, Torrez C, Andre C, Leuliet JC, Fillaudeau L (2000) CFD simulation of food stuff flows in an agitated vessel. In: Proceedings of the 1st International Conference on simulation in Food and Bio Industries. Society of Computer simulation International, The Netherlands 179-186.

41. Aubin J, Xuereb C (2006) Design of Multiple Impeller Stirred Tanks for the mixing of highly viscous fluids using CFD. Chem Eng Sci 61: 2913-2920.

42. De Vries U, Velthuis H, Koster K (1995) Baking ovens and product quality- a computer model. Food Sci Tech Today 9: 232-234.

43. Therdthai N, Zhou W, Adamczak T (2002) Optimization of temperature profile in bread baking. J Food Eng 55: 41-48.

44. Therdthai N, Zhou W (2003) Recent advances in the studies of bread baking process and their impact on the bread baking technology. Food Sci Technol Res 9: 219-226.

45. Zhang J, Datta AK (2006) Mathematical modeling of bread baking process. Food Eng 75: 78-89.

46. Navaneethakrishnan P, Srinivasan PSS, Dhandapani S (2007) Heat transfe and heating rate of food stuffs in commercial shop ovens. Sadhana 32: 535544

47. Wong SY, Zhou W, Hua J (2007) CFD modeling of an industrial continuous bread baking process involving U- movement. J Food eng 78: 888-896.

48. Therdthai N, Zhou W, Adamczak T (2003) Two-dimensional CFD modelling and simulation of industrial continuous bread baking oven. J Food eng 60: 211217.

49. Xia B, Sun DW (2002) Application of CFD in the food industry: a review. Computer and Electronics in Agriculture 34: 5-24.

50. Foster AM, Barrett R, James SJ, Swain MJ (2002) Measurement and prediction of air movement throughout doorways in refrigerated rooms. Int J Refrig 25 $1102-1109$. 
Citation: Kaushal P, Sharma HK (2012) Concept of Computational Fluid Dynamics (CFD) and its Applications in Food Processing Equipment Design. J Food Process Technol 3:138. doi:10.4172/2157-7110.1000138

Page 7 of 7

51. Xiao-hua Q, Jing X, Shi-qiong X (2003) Application of Computational Fluid Dynamics (CFD) in Refrigeration. Refrigeration 1-5

52. Smale NJ, Moureh J, Cortella G (2006) A review of numerical models of airflow in refrigerated food applications. Int J Refrig 29: 911-930.

53. Lv YL, Zhang WH, Gong Y, Tao WQ (2007) Numerical Simulation of Refrigerated Display cabinets. Bio-Inspired Computing: Theories and Applications 258-262.

54. Sun DW (2007) Computational fluid dynamics in food processing. CRC press.

55. Khudheyer AF, Mahmoud Sh (2011) Numerical analysis of fin-tube plate heat exchanger by using CFD technique. ARPN J Engineering and Applied Sciences 6: 1-7.

56. Baerdemaeker JD, Nicolaï BM (1995) Equipment Considerations for sous vide cooking. Food Control 6: 229-236.
57. Janes DA (1996) The art of bakery equipment manufacture: European Food and Drink Review. Autumn 45-46.

58. Pandey SK (2010) CFD simulation of hydrodynamics of three phase fluidized bed. M. Tech Thesis submitted to Department of Chemical Engineering, National Institute of Technology, Rourkela, Orissa, India.

59. Pordal HS (2006) Practicing the Science of Computational Fluid Dynamics. Course Work Report No 513-3366701: 1-76.

60. Eisenga AHM, Foster A, James SJ (1998) CFD prepared for the Process industry, NPT Process technologie, Using CFD in the design of food cooking, cooling and display plant equipment. Paper presented in Second European Symposium on Sous Vide, Belgium. 